\title{
Adult Perfomance on the Sustained Auditory Attention Skill Test
}

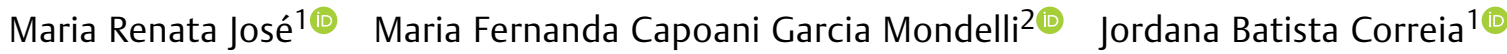 \\ Vanessa Bohn ${ }^{1,4(0)}$ José Roberto Pereira Lauris ${ }^{3(0)}$ Bianca Simone Zeigelboim ${ }^{10}$ \\ Mariza Ribeiro Feniman² ${ }^{2}$
}

${ }^{1}$ Postgraduate Program in Communication Disorders, Universidade Tuiuti do Paraná, Curitiba, PR, Brazil

2 Postgraduate Program in Speech Therapy, Faculdade de Odontologia de Bauru, Universidade de São Paulo, Bauru, SP, Brazil

3 Postgraduate Program in Orthodontics and Dentistry in Collective Health, Faculdade de Odontologia de Bauru, Universidade de São Paulo, Bauru, SP, Brazil

${ }^{4}$ Instituto Superior e Centro Educacional Luterano Bom Jesus, Joinville, SC, Brazil

\begin{abstract}
Address for correspondence Maria Renata José, PhD, Programa de Pós-Graduação em Distúrbios da Comunicação, Diagnóstico e Tratamento em Audição e Equilíbrio, Universidade Tuiuti do Paraná, Rua Sydnei Antônio Rangel, 245, Santo Inácio, 82010330, Curitiba, PR, Brazil (e-mail: maria.renata@utp.br).
\end{abstract}

Int Arch Otorhinolaryngol 2021;25(2):e249-e254.

\begin{abstract}
Introduction The Sustained Auditory Attention Ability Test (SAAAT) is an instrument used to assess sustained auditory attention in children. Difficulties related to this ability are not unique to children alone, as adults have been observed to present with the same deficits. Therefore, there is a need to adapt instruments like the SAAAT and provide reference values for adults.

Objective To assess adult performance on the SAAAT.

Methods Approved by the Human Research Ethics Committee under $n^{\circ}$ 034/2011. The sample consisted of 30 participants aged between 18 and 30 years old (average age $=24.2$ years old), female and male. The inclusion criteria were: peripheral hearing within normal limits, type A tympanometric curve, and no attention-related complaints. The participants were submitted to Tonal Audiometry, Logoaudiometry, Immitanciometry and to the SAAAT.

Results The following mean values and standard deviations (SD) were observed: inattention $=1.7(S D=2.2)$ and impulsivity $=0.8(S D=0.9)$ error types. For the SAAAT, the mean value for the total error score was $2.4(\mathrm{SD}=2.6)$, and for the decrease in vigilance, it was $0.3(S D=0.5)$. When comparing the performance of adults and children, a statistically significant difference was observed for inattention

\section{Keywords}

- attention

- hearing

- adult $(p=0.000)$ and impulsivity $(p=0.001)$ error types, as well as in the total error score $(p=0.000)$ and in decreased vigilance $(p=0.0003)$.

Conclusion The performance of adults in the SAAAT differed from the children's parameters, since adults showed lower scores in all variables of the instrument.
\end{abstract}

received

February 6, 2020

accepted

March 29, 2020

published online

June 23, 2020
DOI https://doi.org/ 10.1055/s-0040-1712481. ISSN 1809-9777.

\footnotetext{
(C) 2020. Fundação Otorrinolaringologia. All rights reserved.

This is an open access article published by Thieme under the terms of the Creative Commons Attribution-NonDerivative-NonCommercial-License, permitting copying and reproduction so long as the original work is given appropriate credit. Contents may not be used for commercial purposes, or adapted, remixed, transformed or built upon. (https://creativecommons.org/ licenses/by-nc-nd/4.0/)

Thieme Revinter Publicações Ltda., Rua do Matoso 170, Rio de Janeiro, RJ, CEP 20270-135, Brazil
} 


\section{Introduction}

Attention is a complex cognitive function, necessary for learning, following behavioral social norms, and performing responsibilities and duties effectively. ${ }^{1}$ Several studies are available on attention in children. However, learning does not occur only during childhood. New skills are acquired throughout a lifespan, and for learning to take place, attention and memory are involved, especially incidental memory. ${ }^{2}$

Attention can be divided into focused attention, selective attention, alternate attention, divided attention and sustained attention. ${ }^{3,4}$ The latter is required in various professional activities in adulthood, such as driving or medicalrelated activities. ${ }^{1}$

The Sustained Auditory Attention Ability Test (SAAAT) is a clinically used instrument to measure sustained auditory attention, which has been translated and adapted for the Brazilian population up to the age of 11 years old..$^{5}$ The SAAAT adaptation study consisted of 6 groups of children aged between 6 and 11 years old, divided by age group (G1: 6 years old; G2: 7 years old; G3: 8 years old; G4: 9 years old; G5: 10 years old, and G6: 11 years old). The study concluded that the SAAAT scores were correlated with the age of the child because the younger the age, the higher the number of errors (inattention and impulsivity), and consequently the higher the total error score. A greater decrease in vigilance was observed in children aged between 6 and 8 years old than in those between 9 and 11 years old.

After its linguistic and cultural adaptation to Brazilian Portuguese, up until the year of 2013, this test was applied exclusively to children. ${ }^{5-9}$ However, it was observed that in clinical practice, adults showed lower SAAAT test scores compared with results found in children 11 years old, as this age was the highest available age range for the test.

The lack of studies investigating sustained auditory attention ability in adults and the observed score difference in the SAAAT when applied to this age group demonstrates a possible need for a valid adult test.

The purpose of the present study is to assess the performance of adults in the SAAAT.

\section{Methods}

The present research project was submitted to the Human Research Ethics Committee of the institution where it was developed, under protocol number 034/2011.

Thirty adults were part of the present study, aged between 18 and 30 years old (mean age $=24.2$ years old; standard deviation $=3.1)$, female $(n=15)$ and male $(n=15)$. The predominant levels of education were completed college (53.3\%; $n=16)$, followed by uncompleted college $(40 \% ; n=12)$ and completed high school $(6.7 \% ; n=2)$. The inclusion criteria for participating in the study were: peripheral hearing within normal range, bilaterally verified by pure tone audiometry, with thresholds considered normal up to 25 decibel level of hearing (dBHL), ${ }^{10}$ as well as normal middle ear function assessed by tympanometry, showing a total of $100 \%$ type A tympanometric curves. ${ }^{11}$ Another inclusion criterion was no complaints related to attention.

The sample population was recruited by invitation to undergraduate students of the institution where the study was conducted and by volunteers living in a country-side city in the state of São Paulo, Brazil. The sample had to have no previous contact with the SAAAT. Participants who did not agree with the procedures or did not sign the Informed Consent Form were excluded from the study.

A questionnaire was included to verify aspects related to attention ability, previously to the application of the proposed procedures. The questionnaire was the one $\mathrm{e}^{7,12}$ used to verify the auditory attention ability in children, but adapted for application in adults.

After applying the attention questionnaire, the participants, who had no attention-related complaints and met the inclusion criteria, were submitted to Tonal Audiometry, Logoaudiometry (Midimate 622 - Madsen Eletronics audiometer, GN Otometrics A/S, Copenhagen, Denmark), Immittance (SD 30; Siemens, Munich, Germany) and the SAAAT for the purpose of assessing sustained hearing attention (Midimate 622 - Madsen Eletronics audiometer, GN Otometrics A/S, Copenhagen, Denmark).

Air thresholds were investigated in an acoustically treated cabin, to verify audiometric thresholds, at frequencies from $250 \mathrm{~Hz}$ to $8,000 \mathrm{~Hz}$ for the right and left ear. The degree of hearing loss was classified using the audiometric thresholds of the frequencies of $500,1,000,2,000$ and $4,000 \mathrm{~Hz}$, classified as mild (mean 26 to $40 \mathrm{dBHL}$ ), moderate (mean 41 to $60 \mathrm{dBHL}$ ), severe (mean 6180 $\mathrm{dBHL}$ ) and deep (mean $>81 \mathrm{dBHL}$ ) according to the World Health Organization (WHO). ${ }^{10}$ When air thresholds $>25$ dBHL were detected, bone audiometry was performed to characterize the type of hearing loss (sensorineural, conductive or mixed). Logoaudiometry was performed to confirm tonal thresholds and to verify word detection and recognition capacity. Afterward, participants underwent immittance monitoring to verify the tympanic-ossicular conditions and the integrity of the auditory pathway. Participants diagnosed with hearing loss were advised of the change found and were referred to a health unit of their choice for appropriate management.

After this stage, all of the participants who met the inclusion criteria completed the SAAAT.

The SAAAT is based on the Auditory Continuous Performance Test (ACPT), ${ }^{13}$ which is clinically employed to measure sustained auditory attention. ${ }^{5}$

The SAAAT $^{5}$ is an instrument used to verify the ability of the subject to hear words over a prolonged period of time (11 minutes). Subjects raise their hand to a specific stimulus (target word "no"). The test contains 21 monosyllabic words arranged in a 100-word list format that is repeated six times without interruption during the test at the rate of one word per second. During the list of 100 words, there is an incidence of the word "no" 20 times, requiring a task of hearing surveillance from the assessed subject. The test was provided in a Compact Disc (CD) format with the aid of a CDP 4147 CD player (Toshiba, Tokyo, Japan), coupled with a Midimate 
Table 1 Mean values, standard deviation and prevalence of inattention errors in males and females

\begin{tabular}{|l|l|l|l|l|l|l|l|}
\hline Gender & $\mathrm{N}$ & Mean & SD & 1st quartile & Median & 3rd quartile & -value \\
\hline Female & 15 & 1.2 & 1.8 & 0.0 & 0.0 & 2.0 & 0.285 \\
\hline Male & 15 & 2.1 & 2.4 & 0.0 & 1.0 & 5.0 & \\
\hline Total & 30 & 1.7 & 2.2 & 0.0 & 0.5 & 4.0 & - \\
\hline
\end{tabular}

Abbreviations: N, Number; SD, standard deviation.

p: the difference between SAAAT variable means in males and females.

Statistical test: Mann-Whitney test.

622 two-channel audiometer (Midimate 622 - Madsen Eletronics, GN Otometrics A/S, Copenhagen, Denmark) and performed diotically (same information in both ears), with an intensity of $50 \mathrm{dBHL}$ above the tritonal average of the frequencies from $500 \mathrm{~Hz}$ to $2,000 \mathrm{~Hz}$.

Participants were verbally instructed by the evaluator that they would hear a list of words and that they should raise their hand whenever they hear the word "NO." The test began only after learning and understanding the test (after the first 50 words). Responses were recorded following a specific protocol with an " $\mathrm{x}$ " in front of each test word for which the participant raised his hand. All evaluations were performed by the same researcher.

Results of the SAAAT include the total error score and the decrease in vigilance. The total error score is obtained by summing the number of inattention (when the participant did not raise his hand when hearing the word "NO" before the next word was presented) with the number of impulsiveness (when the participant raised the hand to another word instead of the word "NO"). The decrease in vigilance, that is, the decline in attention that occurred overtime during the surveillance task, was obtained by calculating the difference between the number of correct answers in the $1^{\text {st }}$ and $6^{\text {th }}$ presentation of the SAAAT word list.

The tests used for statistical analyses were: The MannWhitney Test to verify the association between gender in all SAAAT variables (inattention, impulsivity, total error score, and decreased vigilance). The Spearman correlation test was used to verify the correlation between age and education variables and the variables in the SAAAT. The Spearman correlation coefficient was used to verify the correlation between all SAAAT variables and age. The comparison between the groups of 11 -year-old children ${ }^{5}$ and adults for the variables of inattention, impulsivity, total error score and decreased vigilance was performed using the
Mann-Whitney test. The statistical significance level adopted was $p \leq 0.05$.

\section{Results}

- Table 1 shows the distribution of the mean scores obtained by the participants and the influence of the gender variable, considering the inattention errors, based on the SAAAT results.

- Table 2 shows the distribution of the mean scores obtained by the participants and the influence of the gender variable, considering the impulsivity errors, based on the SAAAT results.

- Table 3 shows the distribution of the mean scores obtained by the participants and the influence of the gender variable, considering the total error score.

-Table 4 shows the distribution of the mean scores obtained by the participants and the influence of the gender variable, considering the decrease in vigilance.

A correlation was obtained with the variables total error score $(R=0.114 ; p=0.547)$, decreased vigilance $(R=-$ $0.220 ; p=0.241)$, inattention $(\mathrm{R}=0.049 ; p=0.793)$ and impulsivity ( $\mathrm{R}=0.077 ; p=0.683)$, to verify the influence of age on the performance of SAAAT in the sampled group. No correlation was observed between age and all SAAAT variables (Statistical Test: Spearman Correlation).

$>$ A correlation was obtained between educational level and total score of errors $(\mathrm{R}=0.098 ; p=0.603)$, decreased vigilance $(\mathrm{R}=-0.352 ; p=0.056)$, inattention $(\mathrm{R}=-0.033 ; p=0.858)$ and impulsivity $(\mathrm{R}=0.121 ; p=0.521)$. No correlation was observed between education level and all SAAAT variables (Statistical Test: Spearman Correlation).

A comparison was made between the group of children aged 11 years old ${ }^{5}$ and the group of adults in the present study, to verify whether there is a statistically significant difference between the two groups, as shown in - Table 5.

Table 2 Mean values, standard deviation and prevalence of impulsivity errors in males and females

\begin{tabular}{|l|l|l|l|l|l|l|l|}
\hline Gender & N & Mean & SD & 1st quartile & Median & 3rd quartile & -value \\
\hline Female & 15 & 0.6 & 0.9 & 0.0 & 0.0 & 1.0 & 0.187 \\
\hline Male & 15 & 1.0 & 0.8 & 0.0 & 1.0 & 2.0 & \\
\hline Total & 30 & 0.8 & 0.9 & 0.0 & 0.5 & 2.0 & - \\
\hline
\end{tabular}

Abbreviations: N, Number; SD, standard deviation.

$\mathrm{p}$ : the difference between SAAAT variable means in males and females.

Statistical test: Mann-Whitney test. 
252 Adult Perfomance on the Sustained Auditory Attention Skill Test José et al.

Table 3 Mean values, standard deviation and prevalence of total error score in males and females

\begin{tabular}{|l|l|l|l|l|l|l|l|}
\hline Gender & N & Mean & SD & 1st quartile & Median & 3rd quartile & $p$-value \\
\hline Female & 15 & 1.8 & 2.1 & 0.0 & 1.0 & 2.0 & 0.232 \\
\hline Male & 15 & 3.1 & 2.8 & 1.0 & 2.0 & 6.0 & \\
\hline Total & 30 & 2.4 & 2.6 & 0.0 & 1.0 & 5.0 & - \\
\hline
\end{tabular}

Abbreviations: N, Number; SD, standard deviation.

$\mathrm{p}$ : the difference between SAAAT variable means in males and females.

Statistical test: Mann-Whitney test.

Table 4 Mean values, standard deviation and prevalence of decrease in vigilance in males and females

\begin{tabular}{|l|l|l|l|l|l|l|l|}
\hline Gender & N & Mean & SD & 1st quartile & Median & 3rd quartile & $p$-value \\
\hline Female & 15 & 0.3 & 0.4 & 0.0 & 0.0 & 1.0 & 0.934 \\
\hline Male & 15 & 0.4 & 0.6 & 0.0 & 0.0 & 1.0 & \\
\hline Total & 30 & 0.3 & 0.5 & 0.0 & 0.0 & 1.0 & - \\
\hline
\end{tabular}

Abbreviations: N, Number; SD, standard deviation.

p: the difference between SAAAT variable means in males and females.

Statistical test: Mann-Whitney test.

Table 5 Mean values and standard deviation for inattention, impulsivity, total error score and decrease in vigilance among the 11year-old and adult groups in the SAAAT

\begin{tabular}{|c|c|c|c|c|c|c|c|c|c|}
\hline \multirow[t]{2}{*}{ Group } & \multirow[t]{2}{*}{$N$} & \multicolumn{2}{|c|}{ Inattention } & \multicolumn{2}{|c|}{ Impulsivity } & \multicolumn{2}{|c|}{ Total Error Score } & \multicolumn{2}{|c|}{$\begin{array}{l}\text { Decrease in Vigi- } \\
\text { lance }\end{array}$} \\
\hline & & Mean & SD & Mean & SD & Mean & SD & Mean & SD \\
\hline Children & 40 & 8.6 & 8.4 & 2.4 & 2.2 & 11.0 & 9.0 & 1.4 & 1.6 \\
\hline Adults & 30 & 1.7 & 2.2 & 0.8 & 0.9 & 2.4 & 2.6 & 0.3 & 0.5 \\
\hline p-value & & \multicolumn{2}{|c|}{$0.000^{*}$} & \multicolumn{2}{|c|}{$0.001^{*}$} & \multicolumn{2}{|c|}{$0.000^{*}$} & \multicolumn{2}{|c|}{$0.003^{*}$} \\
\hline
\end{tabular}

Abbreviations: N, Number; SD, standard deviation.

p: the difference between SAAAT variable means in the group of children and adults

*statistically significant difference.

Statistical test: Mann-Whitney test.

\section{Discussion}

The SAAAT is an instrument used to verify the sustained auditory attention ability in children. However, difficulties related to this ability are not exclusive to children, as they can also be observed in adults. The adaptation of this instrument to the adult population may help provide reference values for adults, investigate this ability in adults, and provide a complementary test to verify the attention ability in the assessment of central auditory processing.

No statistically significant difference was observed between variables (inattention, impulsiveness, total errors and decreased vigilance) and the gender of the participants evaluated ( $\mathbf{- T a b l e s} \mathbf{1}$ to $\mathbf{4}>$ ), which was in agreement with other studies that used the SAAAT in children. ${ }^{5-9}$ According to the results found with adults in the present study, it was observed that gender was not an aspect that influenced the ability of sustained auditory attention. These results were consistent with similar studies with children.

The mean value for inattention errors ( - Table $\mathbf{1}$ ) was 1.7 $(\mathrm{SD}=2.2)$ and for impulsivity (-Table 2) it was 0.8
$(S D=0.9)$. These results were lower than those found in studies with Brazilian children. ${ }^{5-9,14,15}$ As such, there was a decrease in the types of errors found in adults, which may suggest that sustained auditory attention may continue to improve until adulthood.

The total error score (- Table 3) showed a mean of 2.4., ${ }^{2,6}$ These results were lower when compared with studies with Brazilian children. ${ }^{5-9,14,15}$ A study that applied the SAAAT in adults ${ }^{16}$ found mean values of total error scores ranging from $1.00(\mathrm{SD}=1.30)$ to $3.26(\mathrm{SD}=5.86)$. These values were closer to those found in the present study compared with studies with children. ${ }^{5-9,14,15}$ The total error score considers the sum of inattention and impulsivity error types. Thus, a decrease in these types of errors in adults shows that after 11 years old, sustained attention continues to develop until adulthood.

The mean value for the decrease in vigilance ( - Table 4 ) was $0.3(\mathrm{SD}=0.5)$. This result was also lower compared with studies with Brazilian children. ${ }^{5-9,14,15}$ Lima et al ${ }^{16}$ found values between $0.86(\mathrm{SD}=1.18)$ and $0.46(\mathrm{SD}=0.74)$, agreeing with the lowest values in the decrease in vigilance observed in the present study. This result demonstrates 
that adults have greater control over attention span and achieve a better sustained hearing attention maintenance compared with children.

No correlation was observed between age and the SAAAT variables, hence no difference may be inferred whether participants were closer to 18 or 30 years old. These data differed from those found in children, as younger children had worse performance on the SAAAT compared with older children. ${ }^{5}$ Thus, it can be observed that sustained auditory attention ability continues to develop and improve during childhood, while in adulthood it is already consolidated. No change in the performance parameters was observed among adults aged 18 to 30 years old. The total error score and the decrease in vigilance score in the SAAAT can be used as standard norm values for inattention and impulsivity error types.

There was no correlation between education and all the test variables, showing that education level did not influence the SAAAT performance for this group. Picolini et $\mathrm{al}^{8}$ conducted a study that found that 7-year-old children who attended afternoon public schools showed worse SAAAT scores than children who attended private morning schools, observing a possible influence of the type and time period of school on the SAAAT performance. Some studies ${ }^{1,17}$ found a correlation between school years and sustained attention. The Integrated Visual and Auditory Continuous Performance Test software was applied to 400 women, aged 20 to 50 years old (mean age $=34.4$ years old), and the results showed that the higher the education level, the better performance in the sustained attention tests. These data differed from those found in the present study. It is suggested that the small number of participants, as well as the absence of lower educational levels (elementary school and illiterate people), may have influenced the results. It is recommended to include an investigation of educational level and sustained auditory attention in adults in future studies, by including different levels of education and a greater number of participants.

When comparing all SAAAT variables in children and adults (-Table 5), it was found that the mean values obtained in 11year-old children were higher than those found in adults. These findings reinforce the importance of testing this population to verify the performance parameters of adults. A study ${ }^{16}$ using the SAAAT, conducted on adults with and without tinnitus, found better performance in both the study group (tinnitus) and the control group (without tinnitus), as shown by the lower total error score and decreased vigilance in adults compared with children. ${ }^{5-9,14,15}$

Roebuck et $\mathrm{al}^{18}$ conducted a study to verify the influence of stimulus type (verbal and nonverbal) on continuous performance tasks in 31 children (aged 8 to 12 years old) and in 32 adults (aged 18 to 50 years old). The study showed no language, cognitive or auditory changes. The authors found that adults showed lower values of omission errors and percentage of incorrect responses to different stimuli provided. These data agree with the results found in the present study, where adults showed lower amounts of inattention and impulsivity errors compared with 11-yearolds, and consequently a higher performance.
One limitation of the present study was the difficulty in finding current studies in the literature on sustained auditory attention tests applied in adults in the Brazilian population.

\section{Conclusion}

The performance of adults in the SAAAT differed from the parameters used in children, as adults presented with lower scores in the types of inattention and impulsivity error, as well as in the total score of errors and decreased vigilance.

Note

José M. R. performed data collection, tabulation, literature review and manuscript writing; Mondelli M. F. C. G., Correia J. B., Bohn V and Lauris J. R. P. performed the literature review, manuscript writing and final revision; Feniman M. R. was responsible for the project and study design, in addition to general supervision of the performance steps and manuscript elaboration.

\section{Conflict of Interests}

The authors have no conflict of interests to declare.

\section{References}

1 Shiraseb F, Siassi F, Qorbani M, et al. Higher dietary diversity is related to better visual and auditory sustained attention. Br J Nutr 2016;115(08):1470-1480https://www.cambridge.org/core/ product/identifier/S0007114516000428/type/journal_article

2 Kontaxopoulou D, Beratis IN, Fragkiadaki S, et al. Incidental and Intentional Memory: Their Relation with Attention and Executive Functions. Arch Clin Neuropsychol 2017;32(05):519-532https:// academic.oup.com/acn/article-lookup/doi/10.1093/arclin/acx027

3 Joseph JS, Chun MM, Nakayama K. Attentional requirements in a 'preattentive' feature search task. Nature 1997;387(6635):805-807http://www.nature.com/articles/42940

4 Neumann E, DeSchepper BG. Costs and benefits of target activation and distractor inhibition in selective attention. J Exp Psychol Learn Mem Cogn 1991;17(06):1136-1145http://doi.apa.org/getdoi.cfm?doi=10.1037/0278-7393.17.6.1136

5 Feniman MR, Ortelan RR, Lauris JRP, Campos CF, Cruz MS. Proposta de instrumento comportamental para avaliar a atenção auditiva sustentada. Rev Bras Otorrinolaringol 2007;73(04): 523-527 Available from http://www.scielo.br/scielo.php?script= sci_arttext\&pid=S0034-72992007000400011\&lng=pt\&tlng=pt

6 Lemos ICC, Feniman MR. Teste de Habilidade de Atenção Auditiva Sustentada (THAAS) em crianças de sete anos com fissura labiopalatina. Rev Bras Otorrinolaringol (Engl Ed) 2010;76(02): 199-205 Available from http://www.scielo.br/scielo.php?script= sci_arttext\&pid=S1808-86942010000200009\&lng=pt\&nrm =iso \&tlng=en

7 Mondelli MFCG, de Carvalho FRP, Feniman MR, Lauris JRP. Perda auditiva leve: desempenho no Teste da Habilidade de Atenção Auditiva Sustentada. Pró-Fono Rev Atualização Científica [Internet]. 2010 Sep;22(3):245-50. Available from: http://www.scielo. br/scielo.php?script=sci_arttext\&pid=S0104-56872010000300 $015 \& \operatorname{lng}=$ pt\&tlng $=$ pt

8 Picolini M, Stivanin D, Sampaio A, Salvador K, Lauris J, Feniman M. Auditory Attention: Time of Day and Type of School. Arq Int Otorrinolaringol 2010;14(02):174-179 Available from http:// www.thieme-connect.de/DOI/DOI?10.7162/S1809-4872201000 0200005

9 Feniman MR, Rissatto AC, Lauris JR, Mondelli MF. Applicability of the free field Sustained Auditory Attention Ability Test (SAAAT). Int 
254 Adult Perfomance on the Sustained Auditory Attention Skill Test José et al.

Arch Otorhinolaryngol 2012;16(02):269-277http://www.thiemeconnect.de/DOI/DOI?10.7162/S1809-97772012000200017

10 WHO. Grades of hearing impairment. World Health Organization; 2007

11 Jerger J. Clinical experience with impedance audiometry. Arch Otolaryngol 1970;92(04):311-324http://archotol.jamanetwork.com/article.aspx?articleid $=603185$

12 Feniman MR. Aplicação do teste de atenção auditiva FC2 em crianças normais. Faculdade de Odontologia de Bauru - Universidade de São Paulo; 2004

13 Keith RW. ACPT: Auditory Continuous Performance Test. San Antonio: Psychological Corporation; 1994

14 Borba AC, José MR, Verardo LF, Feniman MR. Teste de habilidade de atenção auditiva sustentada em website: aplicabilidade e estudo comparativo. In: Anais do XXIV Congresso Brasileiro de Fonoaudiologia. São Paulo; 2016:8616
15 Fernandes VM. Cortisol salivar e atenção auditiva sustentada. Hospital de Reabilitação de Anomalias Craniofaciais - Universidade de São Paulo; 2017

16 Lima DO, de Araújo AMGD, Branco-Barreiro FCA, Carneiro Cda S, Almeida LNA, da Rosa MRD. Auditory attention in individuals with tinnitus. Braz J Otorhinolaryngol [Internet]. 2019 Mar; Available from: https://linkinghub.elsevier.com/retrieve/pii/S180886941930014X

17 Shiraseb F, Siassi F, Sotoudeh G, et al. Association of blood antioxidants status with visual and auditory sustained attention. Nutr Neurosci 2015;18(08):345-354http://www.tandfonline.com/doi/full/10.1179/1476830515Y.0000000032

18 Roebuck H, Freigang C, Barry JG. Continuous Performance Tasks: Not Just About Sustaining Attention. J Speech Lang Hear Res 2016; 59(03):501-510http://pubs.asha.org/doi/10.1044/2015_JSLHRL-15-0068 